\title{
Management of Hepatorenal Syndrome: A Review
}

\author{
Raseen Tariq ${ }^{1}$ and Ashwani K. Singal*2 \\ ${ }^{1}$ Department of Medicine, Rochester General Hospital, Rochester, NY, USA; ${ }^{2}$ Division of Gastroenterology and Hepatology, \\ University of South Dakota, Sanford School of Medicine, Sioux Falls, SD, USA
}

\begin{abstract}
Acute kidney injury (AKI) occurs frequently in patients with cirrhosis, and hepatorenal syndrome (HRS) is second most common etiology of AKI after volume responsible pre-renal etiology. AKI in these patients negatively impacts pre- and post-transplant patient survival and healthcare burden. Reduced effective blood volume with consequent reduced renal blood flow, along with systemic inflammation in patients with decompensated cirrhosis, result in susceptibility to HRS. In this article, we will review updates over the last 5 years on the changing definition with diagnostic criteria and nomenclature of AKI and HRS, data on medical treatment with vasoconstrictors, and urinary biomarkers in diagnosis of etiology of AKI. We will also discuss the significance of liver transplantation evaluation once the diagnosis of HRS is established and the post-transplant immunosuppression management. We will also review one of the challenging issues that remains among transplant-eligible patients, that of allocation of simultaneous liver kidney transplant. Finally, we will review the new implemented policy from the Organ Procurement Transplant Network on simultaneous liver kidney allocation.
\end{abstract}

Citation of this article: Tariq R, Singal AK. Management of hepatorenal syndrome: A review. J Clin Transl Hepatol 2020;8(2):192-199. doi: 10.14218/JCTH.2020.00011.

\section{Introduction}

Hepatorenal syndrome (HRS) among patients with cirrhosis is one of the most devastating complications, with high mortality if not promptly recognized and properly treated. ${ }^{1,2}$ Portal hypertension in cirrhosis leads to splanchnic arterial vasodilation, which results in reduced systemic vascular resistance and effective circulating blood volume. ${ }^{3}$ Compensatory increase in cardiac output by activation of the renin-angiotensin-aldosterone and sympathetic nervous systems results in vasoconstriction of renal arteries with reduced renal blood flow. These physiological changes combined with hypoalbuminemia from reduced synthetic function of liver lead to sodium and water retention, manifesting as ascites and edema and setting the

Keywords: HRS; Management; Liver transplant for HRS.

Abbreviations: $A C L F$, acute on chronic liver failure; $A K I$, acute kidney injury ATN, acute tubular necrosis; HRS, hepatorenal syndrome; LT, liver transplantation; NO, nitric oxide; SLK, simultaneous liver kidney; TLR4, Toll-like receptor 4. Received: 14 February 2020; Revised: 23 April 2020; Accepted: 8 May 2020 *Correspondence to: Ashwani K. Singal, Division of Gastroenterology and Hepatology, University of South Dakota, Sanford School of Medicine, Transplant Hepatologist and Chief Clinical Research Program, Avera Transplant and Research Institutes, Sioux Falls, SD 57105, USA. Tel: +1-605-322-8545, Fax: +1-605322-8536, E-mail: ashwanisingal.com@gmail.com stage for development of acute kidney injury (AKI) and HRS Inflammation with systemic inflammatory response syndrome in acute on chronic liver failure (ACLF) and decompensated cirrhosis is emerging as another major mechanism for the development of HRS.

In this article, we will review recent updates on the definition and terminology, criteria for diagnosis, emerging biomarkers [in differentiating HRS from intra-renal cause of AKI, especially acute tubular necrosis (ATN)], medical management, and role of liver transplantation (LT), especially for criteria for allocation of simultaneous liver kidney (SLK) transplantation

\section{Prevalence and healthcare burden}

HRS is common among patients with cirrhosis and its occurrence increases with its severity and duration. For example, in a prospective study, the incidence of HRS was $18 \%$ at 1 year and $39 \%$ at 5 years of follow-up. ${ }^{4}$ Another study described the prevalence of HRS in about $48 \%$ of patients listed for $\mathrm{LT}^{5}$ Apart from negative impact on patient survival and outcomes, HRS is associated with huge healthcare cost and significant socio-economic burden. ${ }^{6}$ For example, in a retrospective study on 2542 patients hospitalized with HRS, mean length of hospital stay per patient was 30.5 days, with $\$ 91,504$ per admission. $^{7}$

\section{Definition of AKI and HRS}

Serum creatinine estimation in patients with cirrhosis may not provide true renal function, due to a) malnutrition and muscle atrophy that occur with reduced synthesis of creatinine, b) increased renal tubular secretion of creatinine, c) dilution of serum creatinine due to increased volume of distribution in cirrhotic patients, and d) measurement error when there is cholestasis with elevation of serum bilirubin levels. 8,9 However, in routine practice, serum creatinine continues to be used for monitoring renal function and diagnosing AKI and HRS. This is because the test is simple, inexpensive, readily performed, widely available, and can be repeated frequently during the day. Over the last 10-15 years, the old definition of AKI using serum creatinine cut-off at $1.5 \mathrm{mg} / \mathrm{dL}$ has been changed, since even a minor change from baseline of as little as $0.3 \mathrm{mg} / \mathrm{dL}$ has been found to be associated with worse patient survival among hospitalized patients. ${ }^{10}$ Currently, AKI is defined as increase in serum creatinine of $\geq 0.3 \mathrm{mg} / \mathrm{dL}$ within $48 \mathrm{~h}$ among hospitalized patients, or $\geq 50 \%$ increase over baseline level within the last 3 months among outpatients, or urine volume $<0.5 \mathrm{~mL} /$ $\mathrm{kg} / \mathrm{h}$ for about $6 \mathrm{~h}$. Further, severity of AKI is stratified into three stages: stage 1 defined by increase in serum creatinine $\geq 0.3 \mathrm{mg} / \mathrm{dL}$ or 1.5 - to 2 -fold from baseline; stage 2 defined by increase by 2 - to 3 -fold; and, stage 3 defined by $>3$-fold 
increase or absolute serum creatinine of $\geq 4 \mathrm{mg} / \mathrm{dL}$ or initiation of renal replacement therapy. ${ }^{11}$

Beyond the well-known types of AKI, namely, pre-renal, intrarenal and post-renal, patients with cirrhosis may develop a specific type of renal dysfunction of HRS. ${ }^{12}$ Traditionally, HRS is stratified into types 1 and 2, with $75 \%$ of cases being due to type 1 HRS (rapid rise of creatinine to $>2.5$ $\mathrm{mg} / \mathrm{dL}$ over $1-2$ weeks) with a median survival of $50 \%$ at 2 weeks. ${ }^{5,13}$ In contrast, type 2 HRS, which presents as indolent decrease in renal function is often associated with refractory ascites, with median survival of about 6 months. ${ }^{11,14,15}$ Recently, the nomenclature of HRS types has been modified with 'HRS-AKI' replacing HRS type 1 and 'HRS-CKD' replacing HRS type 2 (Table 1). ${ }^{12}$ Being most common, the current review will focus on the HRS-AKI type.

\section{Pathophysiology of HRS}

Portal hypertension in cirrhosis results in splanchnic vasodilation, with pooling of blood and reduced effective circulating blood volume. ${ }^{16}$ In early stages of cirrhosis, compensatory increase in cardiac output maintains the circulatory volume. However, the susceptibility of such afflicted patients to reduced renal blood flow and AKI is increased with a) hypovolemia (nausea, vomiting, diarrhea, poor oral intake, diuretics, gastrointestinal bleeding, use of non-steroidal anti-inflammatory drugs or radiocontrast agents), b) progressive disease with increasing severity and decompensation of cirrhosis, and c) cirrhotic cardiomyopathy in $40-50 \%$ of patients with cirrhosis and diastolic dysfunction. ${ }^{17}$ The reduced circulating blood volume results in activation of the renin-angiotensin-aldosterone and sympathetic nervous systems, with sodium water retention and reduced renal blood flow occurring due to the vasoconstriction of renal arteries, with development of HRS-AKI (Fig. 1).

Recently, there is a growing line of evidence on the role of inflammation and systemic inflammatory response syndrome in the development of HRS. ${ }^{18,19}$ Systemic inflammation induced either by pathogen-associated molecular patterns or by damageassociated molecular patterns plays a key role in the development of acute decompensation in patients with cirrhosis. ${ }^{12}$

Bacterial translocation from the gut due to increased intestinal permeability with activation of Toll-like receptor 4 (commonly known as TLR4) on hepatic macrophages results in inflammatory response. ${ }^{20}$ Additionally, studies have suggested the up-regulation of renal tubular TLR4, which is associated with the development of renal dysfunction and tubular damage. ${ }^{12}$

The activated inflammatory cascade leads to release of proinflammatory cytokines (tumor necrosis factor-alpha or interleukin-6) and vasodilators [nitric oxide (commonly referred to as NO)]. Studies have also suggested that bacterial translocation plays a predominant role in causing the arterial vasodilation that is seen in advanced liver cirrhosis, occurring by stimulation of NO production and up-regulation mediated by tumor necrosis factor-alpha. ${ }^{21}$ About $30 \%$ of patients with HRS have systemic inflammatory response syndrome, due to sterile inflammation in the absence of bacterial infection. ${ }^{18}$

\section{Diagnosis of HRS}

As soon as the diagnosis of AKI is established, steps are taken to expand the intravascular circulating blood volume, including withholding diuretics and administering intravenous fluid $(1.5 \mathrm{~L}$ of normal saline or $1 \mathrm{gm} / \mathrm{kg}$ of albumin). ${ }^{22}$ Simultaneously, efforts should be made to determine specific intrarenal or post-renal etiology with urine examination and renal ultrasound respectively (Fig. 2). Additionally, patients with ATN versus HRS could be distinguished based on fractional excretion of sodium. It appears that fractional excretion of sodium less than $0.2 \%$ may be clinically useful for distinguishing HRS from ATN. ${ }^{23}$ If renal function does not normalize or improve with/within $48 \mathrm{~h}$ of this strategy and approach, a diagnosis of HRS is established if the work-up is negative for other etiologies of AKI (Fig. 2 and Table 1). ${ }^{15}$

There is emerging data on the utility of plasma and urine biomarkers of renal injury, such as neutrophil gelatinaseassociated lipocalin, human endothelin-1, uromodulin, fatty acid binding protein, epidermal growth factor kidney injury molecule-1, and interlukin-18. In a prospective study, urinary concentration of neutrophil gelatinase-associated lipocalin measured at day 3 of development of AKI was found to be accurate for differentiating ATN from other causes of AKI, with c-statistic of 0.87 (95\% confidence interval of $0.78-0.95$ ). In this study, neutrophil gelatinase-associated lipocalin was also found to independently predict AKI progression and 28-day mortality. ${ }^{24}$ Further studies are needed to validate the utility of neutrophil gelatinase-associated lipocalin before implementing this in routine management of patients with AKI.

\section{Pre-transplant management of HRS}

The medical management of HRS has been shown to improve short-term outcomes; however, long-term outcomes are poor without LT. The aim of the medical therapy is to stabilize the patient until LT and to optimize their pre-transplant condition. The medical therapy includes early treatment of AKI and use of vasoconstrictors. ${ }^{1}$

\section{Early treatment of AKI}

Early recognition and treatment is key to improving both preand post-transplant outcomes of patients with cirrhosis. The

Table 1. New definition and nomenclature of HRS

\begin{tabular}{|c|c|c|c|}
\hline Old name & Old definition & New name & New definition \\
\hline Type 1 HRS & $\begin{array}{l}\Delta \geq 50 \% \text { increase in serum creatinine } \\
\text { from baseline } \\
\Rightarrow \text { Cut-off serum creatinine value } \\
\geq 1.5 \mathrm{mg} / \mathrm{dL}\end{array}$ & HRS-AKI & $\begin{array}{l}\text { Increase in serum creatinine within }<48 \mathrm{~h} \\
\geq 50 \% \text { increase in serum creatinine from baseline } \\
\text { within } \leq 3 \text { months }\end{array}$ \\
\hline Type 2 HRS & $\begin{array}{l}\text { Smoldering increase in serum } \\
\text { creatinine to } \geq 1.5 \mathrm{mg} / \mathrm{dL}\end{array}$ & HRS-CKD* & $\begin{array}{l}\text { Estimated glomerular filtration rate }<60 \mathrm{~mL} / \mathrm{min} \\
\text { per } 1.73 \mathrm{~m}^{2} \text { for } \geq 3 \text { months in the absence of other } \\
\text { (structural) causes }\end{array}$ \\
\hline
\end{tabular}

* Acute kidney disease if increase in serum creatinine is $<50 \%$ from baseline and/or estimated glomerular filtration rate $<60 \mathrm{~mL} / \mathrm{min}$ for $<3 \mathrm{months}$. Abbreviations: AKI, acute kidney injury; CKD, chronic kidney disease; HRS, hepatorenal syndrome. 
Tariq R. et al: Hepatorenal syndrome: A review

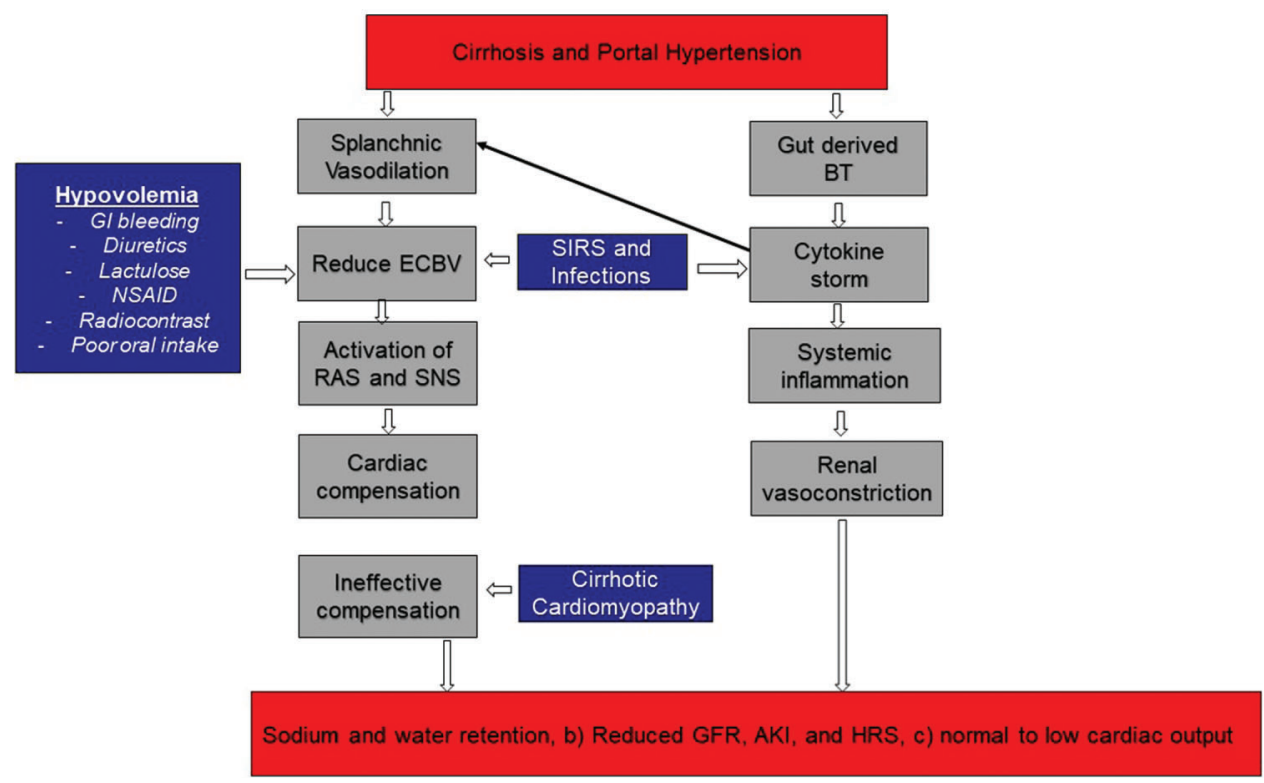

Fig. 1. Pathophysiology of renal dysfunction and HRS in cirrhosis.

Abbreviations: AKI, acute kidney injury; BT, bacterial translocation; ECBV, effective circulating blood volume; GFR, glomerular filtration rate; HRS, hepatorenal syndrome; NSAID, non-steroidal anti-inflammatory drug; RAS, renin-angiotensin system; SIRS, systemic inflammatory response syndrome; SNS, sympathetic nervous system.

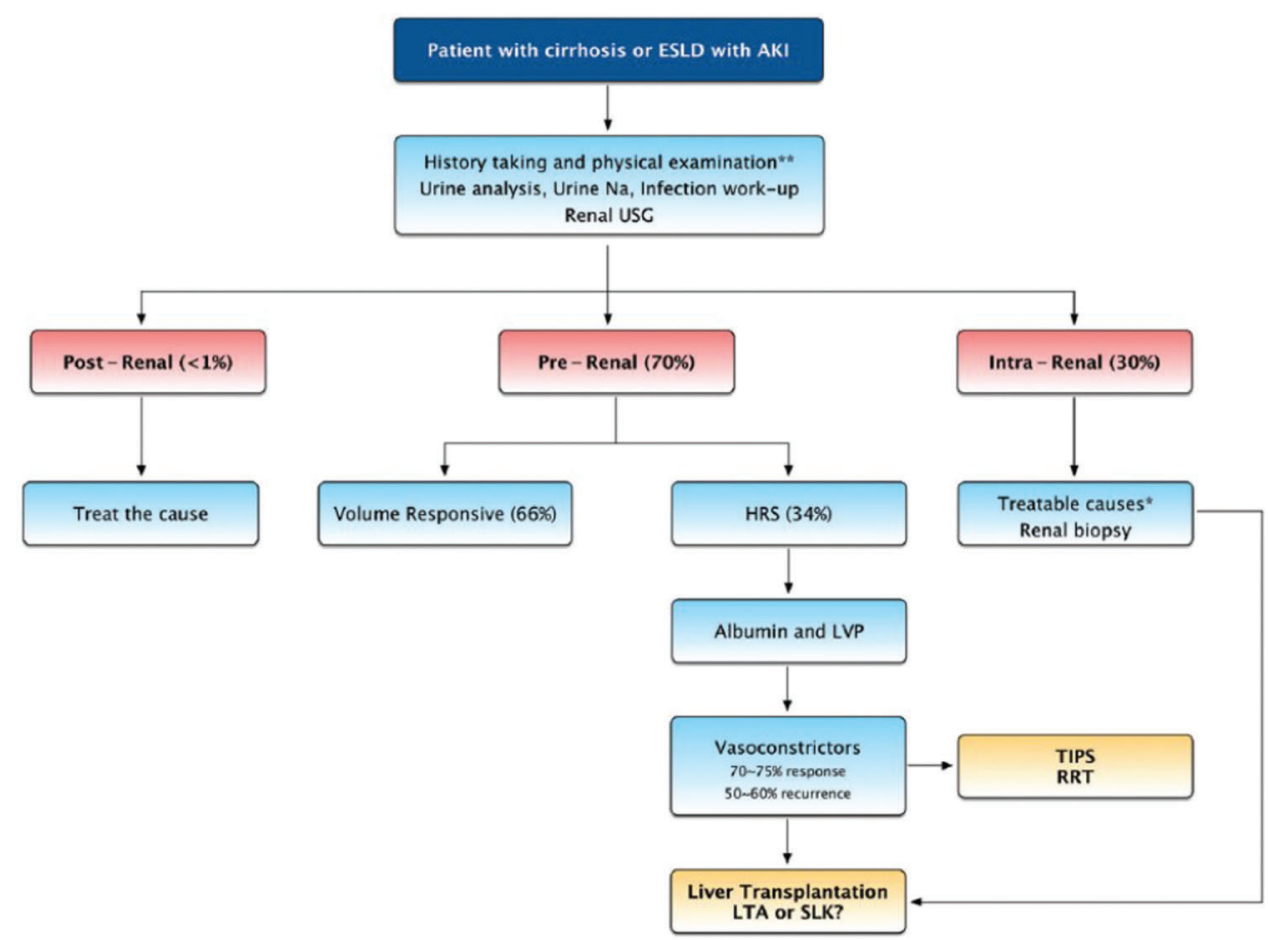

Fig. 2. Management approach and algorithm for AKI in patients with cirrhosis.

Abbreviations: AKI, acute kidney injury; ESLD, end-stage liver disease; LTA, liver transplant alone; LVP, large volume paracentesis; RRT, renal replacement therapy; SLK, simultaneous liver kidney; TIPS, transjugular intrahepatic portosystemic shunt. Reproduced with permission from Russ K et al. ${ }^{2}$

main aim is to identify and treat reversible factors, like dehydration, nephrotoxic medications (diuretics, nonsteroidal anti-inflammatory drugs, aminoglycosides, and angiotensin-converting enzyme inhibitors), infection and sepsis, and gastrointestinal bleeding. ${ }^{25}$ If large volume paracentesis is needed, especially over 3-5 L, intravenous 
albumin replacement should be used with 6-8 $\mathrm{g}$ of albumin for every $1 \mathrm{~L}$ of ascitic fluid removed. Patients with spontaneous bacterial peritonitis should also receive intravenous albumin $(1.5 \mathrm{~g} / \mathrm{kg}$ on day 1 , followed by $1 \mathrm{~g} / \mathrm{kg}$ on day 3$)$, along with antibiotic to improve outcome of these patients. ${ }^{26}$

HRS is a common complication that can occur during acute alcohol hepatitis, having a mortality of about $90 \%$ within 3 months, unless the patient receives liver transplant. Hence, early recognition and treatment for acute alcohol hepatitis is needed with alcohol abstinence supplemental nutrition, and, for select patients, pentoxifylline or corticosteroids. ${ }^{27}$

\section{Prevention of HRS}

Physicians managing patients with cirrhosis should be cognizant of reduced effective circulatory blood volume and renal blood flow, especially with the onset of portal hypertension. These patients should avoid nephrotoxic medications, especially non-steroidal anti-inflammatory drugs. Radiocontrast agents should be used judiciously. Optimization of diuretics should be performed with close follow up of basic metabolic panel and renal function. Further, early identification and treatment of AKI prevents progression and improves patient outcomes. The threshold should be low in using intravenous albumin for expanding fluid volume, especially in hospitalized patients with AKI and spontaneous bacterial peritonitis. For example, in a randomized controlled trial, use of intravenous albumin prevented type- 1 HRS in patients with spontaneous bacterial peritonitis; the trial suggested decreased incidence of HRS (28\% vs. $41 \%)$ and an improvement in 3-month survival ( $94 \%$ vs. $62 \%$ ) in this population, when compared to placebo. ${ }^{28}$

\section{Vasoconstrictor therapy}

Vasoconstrictors cause constriction of splanchnic vessels, resulting in increasing the effective circulating blood volume, which in turn increases renal perfusion and glomerular filtration. ${ }^{11}$ Vasoconstrictors work better when used with intravenous albumin. ${ }^{29}$ Terlipressin is the most common vasopressor used and acts on the V1 receptors on vascular smooth muscle cells. ${ }^{30}$ In a systematic review and metaanalysis of eight randomized trials, terlipressin was associated with $15 \%$ and $9 \%$ reduction of overall and HRS-related mortality respectively. ${ }^{31}$ Another meta-analysis of 309 patients showed mortality benefit with terlipressin, with relative risk of 0.76 (95\% confidence interval of $0.61-0.95) .^{32}$ Although, used extensively throughout the world, terlipressin is not yet approved by the FDA for use in the USA. ${ }^{11} \mathrm{~A}$ recent randomized placebo controlled trial from North America (CONFIRM trial) involving 300 participants (199 receiving terlipressin), HRS reversal was documented in $29.1 \%$ of terlipressin-treated patients compared to $15.8 \%$ of patients receiving placebo $(p<0.012) .{ }^{33}$ Major side effects of terlipressin included abdominal cramps and diarrhea in about $20 \%$ patients and tachyarrhythmias or chest pain in $6 \%$ of patients. Rarely, ischemia of bowel or skin and extremities can occur. ${ }^{32}$ These side effects are less frequent with use of terlipressin as continuous intravenous infusion, as compared to when the drug is applied in intravenous boluses, due to the less daily total dose needed when used as an infusion. ${ }^{34}$

As terlipressin is currently not available in the USA, other vasoconstrictors like norepinephrine, midodrine, and octreotide, are used for the treatment of HRS. Norepinephrine, a catecholamine with predominantly alpha-adrenergic activity, is an inexpensive alternative and widely used as an infusion for the treatment of HRS. ${ }^{35}$ In a meta-analysis of seven trials of norepinephrine compared with terlipressin, the drugs were found to be equally effective in reversal of HRS ( 53 vs. $55 \%, p$ indicated non-significance). ${ }^{36}$

Midodrine, an alpha-adrenergic agent administered orally in combination with subcutaneous octreotide, is another alternative. In a case-control study, use of this combination on $75 \mathrm{HRS}$ patients improved transplant-free survival, overall survival, with better renal function at 1 month compared to historical cohort of 87 HRS patients who did not receive this specific pharmacologic vasoconstrictor therapy. ${ }^{37}$

In the most recent meta-analysis of 13 randomized controlled trials on use of vasoconstrictors for HRS, terlipressin was the most effective agent for HRS reversal and norepinephrine was as effective as terlipressin. However, both these drugs were superior to midodrine and octreotide combination for HRS survival. ${ }^{38}$ None of the drugs showed any benefit on HRS relapse or on patient survival. Based on these data, until terlipressin is available for use in the USA, norepinephrine remains the drug of choice, especially for patients treated in the intensive care unit, and the midodrine/octreotide combination is reserved for patients treated on the medical floor (Table 2).

Most patients are treated for 2 weeks at least before declaring non-response and discontinuation of the specific medication. As mentioned earlier, to achieve maximum efficacy, vasoconstrictors are used in combination with intravenous albumin infusion. Among responders, midodrine is usually continued indefinitely or until LT. In one study, outpatient terlipressin infusion as a bridge to LT has been reported in six patients after HRS reversal was documented, with three patients successfully bridged to LT. ${ }^{39}$ Further prospective studies are needed to evaluate the role and regimen of this approach as basis for maintaining renal function and bridging patients to LT. The role of vasoconstrictors for type 2 HRS or HRS-CKD remains unclear and most studies have been performed on HRS-AKI patients. In a non-randomized study, terlipressin was associated with improved renal function in patients with type 2 HRS. ${ }^{40}$ Further good quality randomized data is needed to evaluate the efficacy and long-term safety of these agents in patients with HRS-CKD.

\section{Miscellaneous therapies}

Few studies have evaluated the efficacy of transjugular intrahepatic portosystemic stent-shunt for HRS. Two small case series found improvement in renal function and survival in patients who underwent transjugular intrahepatic portosystemic stent-shunt for HRS. ${ }^{41,42}$ However, transjugular intrahepatic portosystemic stent-shunt is a risky procedure and patients with HRS are usually too sick to undergo this procedure. Until benefit of transjugular intrahepatic portosystemic stent-shunt is documented in randomized controlled trials, the procedure is not recommended in the management of HRS. Renal replacement therapy can be used as a bridge to LT in patients who fail medical therapy. ${ }^{14}$ The indications for renal replacement therapy in these patients are the same as for any other cause of AKI and include volume overload with $10 \%$ or more weight gain, hyperkalemia, symptomatic uremia, pericarditis, and acidosis. Risks of dialysis include hypotension, infection, and bleeding. Additionally, the exact mode of dialysis for these patients remains unknown. There is 
Tariq R. et al: Hepatorenal syndrome: A review

Table 2. Studies describing various therapies for HRS

\begin{tabular}{|c|c|c|c|}
\hline Study name & Type of study & Intervention & Outcome assessed \\
\hline Hiremanth et al. ${ }^{31}$ & Meta-analysis & Terlipressin & $15 \%$ reduction in overall mortality. \\
\hline Gludd et al. ${ }^{32}$ & Meta-analysis & Terlipressin & Overall reduction in mortality 0.76 (95\% CI: 0.61-0.95). \\
\hline Isralesen et al. ${ }^{36}$ & Meta-analysis & $\begin{array}{l}\text { Norepinephrine } \\
\text { vs. terlipressin }\end{array}$ & Equally effective in reversal of HRS ( 53 vs. $55 \%, p=N S$ ). \\
\hline CONFIRM trial ${ }^{33}$ & RCT & $\begin{array}{l}\text { Terlipressin vs. } \\
\text { placebo }\end{array}$ & $\begin{array}{l}\text { HRS reversal was documented in } 29.1 \% \text { of terlipressin-treated } \\
\text { patients vs. } 15.8 \% \text { patients receiving placebo }(p<0.012)\end{array}$ \\
\hline Skagen et al. ${ }^{37}$ & Case control & $\begin{array}{l}\text { Midodrine and } \\
\text { octroetide }\end{array}$ & $\begin{array}{l}\text { Transplant-free survival was higher compared with the control arm } \\
\text { (median survival } 101 \text { days vs. } 18 \text { days, } p<0.0001 \text { ). }\end{array}$ \\
\hline Nanda et al. ${ }^{38}$ & Meta-analysis & $\begin{array}{l}\text { All drugs } \\
\text { available for } \\
\text { HRS }\end{array}$ & $\begin{array}{l}\text { Terlipressin plus albumin was more efficacious than placebo plus } \\
\text { albumin }(\mathrm{OR}=4.72 ; 95 \% \mathrm{CI}: 1.72-12.93 ; p=0.003) \text { or midodrine plus } \\
\text { albumin and octreotide (OR=5.94; } 95 \% \mathrm{CI}: 1.69-20.85 ; p=0.005) \text {, } \\
\text { for HRS reversal. No significant difference was noted comparing } \\
\text { terlipressin plus albumin versus noradrenaline plus albumin. }\end{array}$ \\
\hline
\end{tabular}

Abbreviations: CI, confidence interval; HRS, hepatorenal syndrome; NS, non-significant; OR, odds ratio.

no evidence on survival benefit with renal replacement therapy among patients not eligible for LT. ${ }^{43}$ Molecular absorbent recirculating system by extra-corporeal albumin dialysis has been proposed as a treatment of refractory ACLF. In a randomized study of 166 patients, survival was similar in patients receiving standard of care $(n=81)$ and patients treated with extra-corporeal albumin dialysis $(n=85)$. However, extra-corporeal albumin dialysis was superior in improving encephalopathy, reducing bilirubin, and improving serum creatinine. Based on these data, extra-corporeal albumin dialysis may be an alternative option to bridge patients with HRS to $\mathrm{LT}^{44}$

\section{Liver transplantation for HRS}

Liver transplantation is the definitive treatment for HRS and can be considered as soon as diagnosis of HRS is established. HRS patients, even after successful medical therapy and reversal of HRS, have poorer post-transplant outcomes than patients without HRS. In one study, of 104 patients, 33 with HRS had longer intensive care unit stay with higher use of hospital resources (including dialysis and blood transfusion), poorer renal function at 1 year, and worse patient survival. However, the patient survival rate at 5 years was satisfactory, at about $80 \%$, justifying its use in these HRS. ${ }^{45}$ It should be recognized that HRS patients with longer duration of renal dysfunction prior to LT may not recover renal function after LT. In another study, about $6 \%$ increased risk of non-recovery of renal function was shown with each additional day of pretransplant dialysis. ${ }^{46}$

\section{Simultaneous liver kidney allocation}

Since the introduction of the model for end-stage liver disease scoring system, a proportion of all LT receiving simultaneous liver kidney (SLK) has increased from $4 \%$ in 2002 to $10 \%$ in $2016.47,48$ Selection of candidates for SLK is a challenge for the hepatology and nephrology transplant community, as there are no good predictors for recovery of renal function after LT alone. ${ }^{49,50}$ In general, SLK transplantation provides survival benefit over LT alone to patients with serum creatinine $>2 \mathrm{mg} / \mathrm{dL}$ and/or patients on hemodialysis. However, the data are scanty on the duration of renal dysfunction or of dialysis in predicting recovery of renal function after LT alone. Criteria for SLK allocation are therefore based on consensus recommendations and without good scientific data, which explains the increasing use of SLK and also the heterogeneity of their use across the regions and also between centers within the region (Table 3 ). ${ }^{49}$

The Organ Procurement Transplant Network introduced a new policy in 2016 for SLK allocation, with the following criteria: A) for chronic kidney disease: a) glomerular filtration rate of $<60 \mathrm{~mL} / \mathrm{min}$ for 90 days and subsequent glomerular filtration rate of $<30 \mathrm{~mL} / \mathrm{min}$ or initiation of dialysis, b) chronic kidney disease due to metabolic disease that can be corrected with a liver transplant (hyperoxaluria, atypical hemolytic uremic syndrome, familial non-neuropathic systemic amyloidosis, and methylmalonic aciduria); and B) for AKI: a) duration of AKI $>6$ weeks with persistent glomerular filtration rate of $<20 \mathrm{~mL} / \mathrm{min}$, b) need of dialysis for $>6$ weeks, or combination of both the criteria meeting 5 weeks duration. Under this policy, the respective criteria need to be documented every 7 days to maintain listing for SLK. ${ }^{51} \mathrm{~A}$ recent study examined the effects of the implementation of the Organ Procurement Transplant Network policy on 40,979 candidates, of which 1683 met the new criteria, 2452 met the old criteria, and 1878 met both the criteria. They found that patients meeting the new criteria were less likely to die posttransplant. $^{52}$ Further studies are needed for continuous

Table 3. Indications for considering SLK

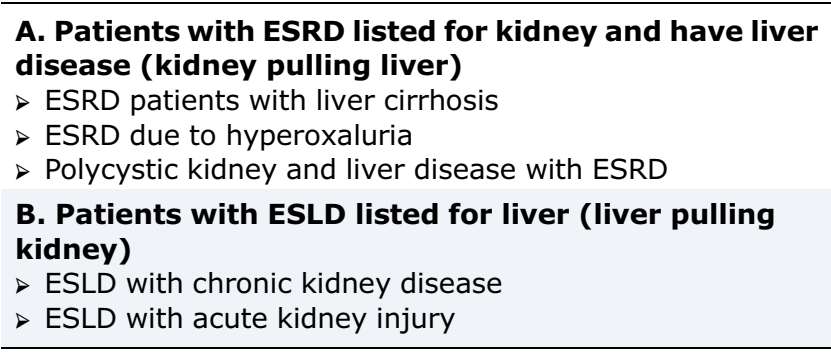

Abbreviations: ESRD, end-stage renal disease; ESLD, end-stage liver disease; SLK, simultaneous liver kidney. 
monitoring of SLK outcomes with the implementation of the new policy.

Whether urinary or plasma biomarkers of tubular injury can improve optimal allocation of SLK was tested in a small open study. However, none of the biomarkers tested within 30 days prior to LT among patients with cirrhosis and AKI were useful in predicting recovery of renal function after LT alone. ${ }^{53}$ There remains unmet need of accurate biomarkers for differentiation of HRS from ATN and predictors using clinical variables or biomarkers or combination of both for recovery of renal function after LT alone, as basis for optimal SLK allocation and use of already scarce donor kidney pool.

\section{Post-transplant management}

Common risk factors for the development of end-stage renal disease during the post-transplant period include calcineurin inhibitor nephrotoxicity, pre-transplant HRS, pre-existing renal insufficiency, and diabetes mellitus. ${ }^{54-56}$ Additionally, episodes of acute renal failure, renal replacement therapy pre- and post-transplantation, hepatitis $\mathrm{C}$ infection, and increasing age have been shown to be associated with risk of chronic kidney disease in the post-transplant period. ${ }^{57-59}$

Given the significant nephrotoxic effects of calcineurin inhibitor, renal-sparing regimens have been used for preserving renal function in the post-transplant period among patients receiving LT for HRS. For example, use of renalsparing approaches have been effective to preserve renal function during the post-transplant period, such as with a) interleukin-2 receptor antagonists (daclizumab, or basiliximab) or polyclonal antibodies (rabbit anti-thymocyte globulin) for induction of immunosuppression and delaying the introduction of calcineurin inhibitor, and b) mTOR inhibitors, such as everolimus or low-dose calcineurin inhibitor, with other agents, like mycophenolate, for maintaining the immunosuppression. ${ }^{60-62}$

\section{Role of palliative care}

Patients with progressive HRS and those ineligible for LT have high short-term mortality with huge healthcare burden. For example, in a study using the national in-patient sample on hospitalized cirrhosis patients who were denied LT, multiple somatic symptoms were experienced with poor quality of life, and this was associated with prolonged hospitalization and higher use of hospital resources. Only $11 \%$ of these patients received palliative care consultation. ${ }^{63}$ Consideration should be given on a case-by-case basis, to discuss the goals of care with the patient and families. ${ }^{63}$ Future research should evaluate timing and effects of palliative care on quality of end-oflife care in this population.

\section{Conclusions}

HRS is a serious complication among patients with liver cirrhosis and is associated with poor prognosis. With recent advances in therapeutic strategies due to better understanding of pathophysiology, there is a hope to reduce its prevalence and improve patient outcomes. Terlipressin and norepinephrine infusion are effective vasoconstrictors, and midodrine combined with octreotide is an alternative option. With the encouraging data from a recently completed multicenter trial in the USA, it is hoped that terlipressin will be approved by the Federal Drug Administration for clinical use in the USA. Vasoconstrictors provide better efficacy when combined with intravenous albumin. Neutrophil gelatinase-associated lipocalin at day 3 of onset of AKI is a promising tool for differentiating intrarenal etiology from HRS; however, larger prospective data are needed as basis for validation before implementing into routine clinical practice. Lack of accurate models for predicting renal function recovery after LT has resulted in increase in the use of SLK in these patients. It is hopeful that the recently introduced Organ Procurement Transplant Network policy for SLK allocation and listing would optimize the use of SLK and help the already scarce kidney donor pool. There remains a clinical unmet need for better and more accurate models predictive of renal function recovery after LT and non-invasive urine or plasma biomarkers for accurate diagnosis of HRS.

\section{Funding}

None to declare.

\section{Conflict of interest}

The authors have no conflict of interests related to this publication.

\section{Author contributions}

Drafted the first version of the manuscript (RT), edited and revised the manuscript, and contributed to conceptual development of the study (AKS).

\section{References}

[1] Pillebout E. Hepatorenal syndrome. Nephrol Ther 2014;10:61-68. doi: 10. 1016/j.nephro.2013.11.005.

[2] Russ KB, Stevens TM, Singal AK. Acute kidney injury in patients with cirrhosis. J Clin Transl Hepatol 2015;3:195-204. doi: 10.14218/JCTH.2015.00015.

[3] Epstein M. Hepatorenal syndrome: emerging perspectives of pathophysiology and therapy. J Am Soc Nephrol 1994;4:1735-1753.

[4] Ginès A, Escorsell A, Ginès P, Saló J, Jiménez W, Inglada L, et al. Incidence, predictive factors, and prognosis of the hepatorenal syndrome in cirrhosis with ascites. Gastroenterology 1993;105:229-236. doi: 10.1016/00165085(93)90031-7.

[5] Wong LP, Blackley MP, Andreoni KA, Chin H, Falk RJ, Klemmer PJ. Survival of liver transplant candidates with acute renal failure receiving renal replacement therapy. Kidney Int 2005;68:362-370. doi: 10.1111/j.1523-1755. 2005.00408.x.

[6] Rice JB, White AG, Galebach P, Korenblat KM, Wagh A, Lovelace B, et al. The burden of hepatorenal syndrome among commercially insured and Medicare patients in the United States. Curr Med Res Opin 2017;33:1473-1480. doi: 10.1080/03007995.2017.1331211.

[7] Jamil K, Huang X, Lovelace B, Pham AT, Lodaya K, Wan G. The burden of illness of hepatorenal syndrome (HRS) in the United States: a retrospective analysis of electronic health records. J Med Econ 2019;22:421-429. doi: 10. 1080/13696998.2019.1580201.

[8] Wong F, Nadim MK, Kellum JA, Salerno F, Bellomo R, Gerbes A, et al. Working Party proposal for a revised classification system of renal dysfunction in patients with cirrhosis. Gut 2011;60:702-709. doi: 10.1136/gut.2010.236133.

[9] Caregaro L, Menon F, Angeli P, Amodio P, Merkel C, Bortoluzzi A, et al. Limitations of serum creatinine level and creatinine clearance as filtration markers in cirrhosis. Arch Intern Med 1994;154:201-205. doi: 10. 1001/archinte.1994.00420020117013.

[10] Nadim MK, Kellum JA, Davenport A, Wong F, Davis C, Pannu N, et al. Hepatorenal syndrome: the 8th International Consensus Conference of the Acute Dialysis Quality Initiative (ADQI) Group. Crit Care 2012;16:R23. doi: $10.1186 /$ cc11188.

[11] Angeli $P$, Ginès $P$, Wong $F$, Bernardi $M$, Boyer TD, Gerbes $A$, et al. Diagnosis and management of acute kidney injury in patients with cirrhosis: revised consensus recommendations of the International Club of Ascites. J Hepatol 2015;62:968-974. doi: 10.1016/j.jhep.2014.12.029. 
[12] Angeli P, Garcia-Tsao G, Nadim MK, Parikh CR. News in pathophysiology, definition and classification of hepatorenal syndrome: A step beyond the International Club of Ascites (ICA) consensus document. J Hepatol 2019; 71:811-822. doi: 10.1016/j.jhep.2019.07.002.

[13] Salerno F, Gerbes A, Ginès P, Wong F, Arroyo V. Diagnosis, prevention and treatment of hepatorenal syndrome in cirrhosis. Postgrad Med J 2008;84: 662-670. doi: 10.1136/gut.2006.107789.

[14] Ginès $P$, Schrier RW. Renal failure in cirrhosis. N Engl J Med 2009;361:12791290. doi: 10.1056/NEJMra0809139.

[15] Garcia-Tsao G, Parikh CR, Viola A. Acute kidney injury in cirrhosis. Hepatology 2008;48:2064-2077. doi: 10.1002/hep.22605.

[16] Schrier RW, Arroyo V, Bernardi M, Epstein M, Henriksen JH, Rodés J. Peripheral arterial vasodilation hypothesis: a proposal for the initiation of renal sodium and water retention in cirrhosis. Hepatology 1988;8:1151-1157. doi: $10.1002 /$ hep. 1840080532 .

[17] Ruiz-del-Arbol L, Monescillo A, Arocena C, Valer P, Ginès P, Moreira V, et al. Circulatory function and hepatorenal syndrome in cirrhosis. Hepatology 2005;42:439-447. doi: 10.1002/hep.20766.

[18] Bernardi M, Moreau R, Angeli P, Schnabl B, Arroyo V. Mechanisms of decompensation and organ failure in cirrhosis: From peripheral arterial vasodilation to systemic inflammation hypothesis. J Hepatol 2015;63:1272-1284. doi: 10.1016/j.jhep.2015.07.004.

[19] Sujan R, Cruz-Lemini M, Altamirano J, Simonetto DA, Maiwall R, Axley $P$, et al. A validated score predicts acute kidney injury and survival in patients with alcoholic hepatitis. Liver Transpl 2018;24:1655-1664. doi: 10.1002/lt. 25328.

[20] Shah N, Mohamed FE, Jover-Cobos M, Macnaughtan J, Davies N, Moreau R, et al. Increased renal expression and urinary excretion of TLR4 in acute kidney injury associated with cirrhosis. Liver Int 2013;33:398-409. doi: 10.1111/liv.12047.

[21] Wiest R, Das S, Cadelina G, Garcia-Tsao G, Milstien S, Groszmann RJ. Bacterial translocation in cirrhotic rats stimulates eNOS-derived NO production and impairs mesenteric vascular contractility. J Clin Invest 1999;104:12231233. doi: $10.1172 / J C I 7458$.

[22] Tandon P, James MT, Abraldes JG, Karvellas CJ, Ye F, Pannu N. Relevance of new definitions to incidence and prognosis of acute kidney injury in hospitalized patients with cirrhosis: A retrospective population-based cohort study. PLoS One 2016;11:e0160394. doi: 10.1371/journal.pone.0160394.

[23] Diamond JR, Yoburn DC. Nonoliguric acute renal failure associated with a low fractional excretion of sodium. Ann Intern Med 1982;96:597-600. doi: 10. 7326/0003-4819-96-5-597.

[24] Huelin P, Solà E, Elia C, Solé C, Risso A, Moreira R, et al. Neutrophil gelatinase-associated lipocalin for assessment of acute kidney injury in cirrhosis: A prospective study. Hepatology 2019;70:319-333. doi: 10.1002/hep. 30592.

[25] Terra C, Guevara M, Torre A, Gilabert R, Fernández J, Martín-Llahí M, et al. Renal failure in patients with cirrhosis and sepsis unrelated to spontaneous bacterial peritonitis: value of MELD score. Gastroenterology 2005;129: 1944-1953. doi: 10.1053/j.gastro.2005.09.024.

[26] Sort P, Navasa M, Arroyo V, Aldeguer X, Planas R, Ruiz-del-Arbol L, et al. Effect of intravenous albumin on renal impairment and mortality in patients with cirrhosis and spontaneous bacterial peritonitis. N Engl J Med 1999;341: 403-409. doi: 10.1056/NEJM199908053410603.

[27] Mitchell MC, Friedman LS, McClain CJ. Medical management of severe alcoholic hepatitis: Expert review from the clinical practice updates committee of the AGA institute. Clin Gastroenterol Hepatol 2017;15:5-12. doi: 10.1016/j. cgh.2016.08.047.

[28] Fernández J, Navasa M, Planas R, Montoliu S, Monfort D, Soriano G, et al. Primary prophylaxis of spontaneous bacterial peritonitis delays hepatorenal syndrome and improves survival in cirrhosis. Gastroenterology 2007;133: 818-824. doi: 10.1053/j.gastro.2007.06.065.

[29] Solà E, Cárdenas A, Ginès P. Results of pretransplant treatment of hepatorenal syndrome with terlipressin. Curr Opin Organ Transplant 2013;18:265270. doi: 10.1097/MOT.0b013e3283614c7a.

[30] Barbano B, Sardo L, Gigante A, Gasperini ML, Liberatori M, Giraldi GD, et al. Pathophysiology, diagnosis and clinical management of hepatorenal syndrome: from classic to new drugs. Curr Vasc Pharmacol 2014;12:125-135. doi: $10.2174 / 157016111201140327163930$.

[31] Hiremath SB, Srinivas LD. Survival benefits of terlipressin and non-responder state in hepatorenal syndrome: a meta-analysis. Indian J Pharmacol 2013;45:54-60. doi: 10.4103/0253-7613.106436.

[32] Gluud LL, Christensen K, Christensen E, Krag A. Terlipressin for hepatorenal syndrome. Cochrane Database Syst Rev 2012:CD005162. doi: 10. 1002/14651858.CD005162.pub3.

[33] Kunzmann K. Terlipressin Improves Survival Rates of Lower-MAP Patients with HRS-1. 2018. Available from: https://www.mdmag.com/conferencecoverage/aasld-2018/terlipressin-improves-survival-rates-of-lowermappatients-with-hrs1.

[34] Cavallin M, Piano S, Romano A, Fasolato S, Frigo AC, Benetti G, et al. Terlipressin given by continuous intravenous infusion versus intravenous boluses in the treatment of hepatorenal syndrome: A randomized controlled study. Hepatology 2016;63:983-992. doi: 10.1002/hep.28396.

[35] Duvoux C, Zanditenas D, Hézode C, Chauvat A, Monin JL, Roudot-Thoraval F, et al. Effects of noradrenalin and albumin in patients with type I hepatorenal syndrome: a pilot study. Hepatology 2002;36:374-380. doi: 10.1053/jhep.2002. 34343.

[36] Israelsen M, Krag A, Allegretti AS, Jovani M, Goldin AH, Winter RW, et al. Terlipressin versus other vasoactive drugs for hepatorenal syndrome. Cochrane Database Syst Rev 2017;9:CD011532. doi: 10.1002/14651858.CD011532.pub2.

[37] Skagen C, Einstein M, Lucey MR, Said A. Combination treatment with octreotide, midodrine, and albumin improves survival in patients with type 1 and type 2 hepatorenal syndrome. J Clin Gastroenterol 2009;43:680-685. doi: 10.1097/MCG.0b013e318188947c.

[38] Nanda A, Reddy R, Safraz H, Salameh H, Singal AK. Pharmacological therapies for hepatorenal syndrome: A systematic review and meta-analysis. J Clin Gastroenterol 2018;52:360-367. doi: 10.1097/MCG.0000000000000913.

[39] Vasudevan A, Ardalan Z, Gow P, Angus P, Testro A. Efficacy of outpatient continuous terlipressin infusions for hepatorenal syndrome. Hepatology 2016;64:316-318. doi: 10.1002/hep.28325.

[40] Ortega R, Ginès P, Uriz J, Cárdenas A, Calahorra B, De Las Heras D, et al. Terlipressin therapy with and without albumin for patients with hepatorenal syndrome: results of a prospective, nonrandomized study. Hepatology 2002; 36:941-948. doi: 10.1053/jhep.2002.35819.

[41] Guevara M, Ginès P, Bandi JC, Gilabert R, Sort P, Jiménez W, et al. Transjugular intrahepatic portosystemic shunt in hepatorenal syndrome: effects on renal function and vasoactive systems. Hepatology 1998;28:416-422. doi: 10.1002/hep.510280219.

[42] Wong F, Pantea L, Sniderman K. Midodrine, octreotide, albumin, and TIPS in selected patients with cirrhosis and type 1 hepatorenal syndrome. Hepatology 2004;40:55-64. doi: 10.1002/hep.20262.

[43] Keller F, Heinze $H$, Jochimsen F, Passfall J, Schuppan D, Büttner P. Risk factors and outcome of 107 patients with decompensated liver disease and acute renal failure (including 26 patients with hepatorenal syndrome): the role of hemodialysis. Ren Fail 1995;17:135-146. doi: 10.3109/08860229509026250.

[44] Bañares R, Nevens F, Larsen FS, Jalan R, Albillos A, Dollinger M, et al. Extracorporeal albumin dialysis with the molecular adsorbent recirculating system in acute-on-chronic liver failure: the RELIEF trial. Hepatology 2013;57: 1153-1162. doi: 10.1002/hep.26185.

[45] Chok KS, Fung JY, Chan SC, Cheung TT, Sharr WW, Chan AC, et al. Outcomes of living donor liver transplantation for patients with preoperative type 1 hepatorenal syndrome and acute hepatic decompensation. Liver Transpl 2012;18:779-785. doi: 10.1002/lt.23401.

[46] Wong F, Leung W, Al Beshir M, Marquez M, Renner EL. Outcomes of patients with cirrhosis and hepatorenal syndrome type 1 treated with liver transplantation. Liver Transpl 2015;21:300-307. doi: 10.1002/It.24049.

[47] Organ procurement and transplantation network. Available from: https: //optn.transplant.hrsa.gov/data/.

[48] Singal AK, Salameh H, Kuo YF, Wiesner RH. Evolving frequency and outcomes of simultaneous liver kidney transplants based on liver disease etiology. Transplantation 2014;98:216-221. doi: 10.1097/TP.0000000000000048.

[49] O'Leary JG, Levitsky J, Wong F, Nadim MK, Charlton M, Kim WR. Protecting the kidney in liver transplant candidates: practice-based recommendations from the American Society of Transplantation Liver and Intestine Community of Practice. Am J Transplant 2016;16:2516-2531. doi: 10.1111/ajt.13790.

[50] Singal AK, Ong S, Satapathy SK, Kamath PS, Wiesner RH. Simultaneous liver kidney transplantation. Transpl Int 2019;32:343-352. doi: 10.1111/tri.13388.

[51] Wadei HM, Gonwa TA, Taner CB. Simultaneous liver kidney transplant (SLK) allocation policy change proposal: Is it really a smart move? Am J Transplant 2016;16:2763-2764. doi: 10.1111/ajt.13844.

[52] Cullaro G, Hirose R, Lai JC. Changes in simultaneous liver-kidney transplant allocation policy may impact postliver transplant outcomes. Transplantation 2019;103:959-964. doi: 10.1097/TP.0000000000002403.

[53] Singal AK, Jackson B, Pereira GB, Russ KB, Fitzmorris PS, Kakati D, et al. Biomarkers of renal injury in cirrhosis: association with acute kidney injury and recovery after liver transplantation. Nephron 2018;138:1-12. doi: 10 . $1159 / 000479074$.

[54] Davis CL, Gonwa TA, Wilkinson AH. Identification of patients best suited for combined liver-kidney transplantation: part II. Liver Transpl 2002;8:193211. doi: $10.1053 /$ jlts.2002.32504.

[55] Pawarode A, Fine DM, Thuluvath PJ. Independent risk factors and natural history of renal dysfunction in liver transplant recipients. Liver Transpl 2003;9:741-747. doi: 10.1053/jlts.2003.50113.

[56] Platz KP, Mueller AR, Blumhardt G, Bachmann S, Bechstein WO, Kahl A, et al. Nephrotoxicity following orthotopic liver transplantation. A comparison between cyclosporine and FK506. Transplantation 1994;58:170-178.

[57] Ojo AO, Held PJ, Port FK, Wolfe RA, Leichtman AB, Young EW, et al. Chronic renal failure after transplantation of a nonrenal organ. N Engl J Med 2003; 349:931-940. doi: 10.1056/NEJMoa021744.

[58] Velidedeoglu E, Crawford MD, Desai NM, Campos L, Abt PL, Markmann JW, et al. Predictors of late kidney dysfunction post-liver transplantation. 
Tariq R. et al: Hepatorenal syndrome: A review

Transplant Proc 2002;34:3315-3316. doi: 10.1016/s0041-1345(02) 03627-8.

[59] Gayowski T, Singh N, Keyes L, Wannstedt CF, Wagener MM, Vargas H, Laskus T, Rakela J, Fung JJ, Marino IR. Late-onset renal failure after liver transplantation: role of posttransplant alcohol use. Transplantation 2000;69:383388. doi: 10.1097/00007890-200002150-00013.

[60] Neuberger JM, Mamelok RD, Neuhaus P, Pirenne J, Samuel D, Isoniemi H, et al. Delayed introduction of reduced-dose tacrolimus, and renal function in liver transplantation: the 'ReSpECT' study. Am J Transplant 2009;9:327336. doi: 10.1111/j.1600-6143.2008.02493.x.

[61] Boudjema K, Camus C, Saliba F, Calmus Y, Salamé E, Pageaux G, et al. Reduced-dose tacrolimus with mycophenolate mofetil vs. standard-dose tacrolimus in liver transplantation: a randomized study. Am J Transplant 2011;11:965-976. doi: 10.1111/j.1600-6143.2011.03486.x.

[62] Cicinnati VR, Yu Z, Klein CG, Sotiropoulos GC, Saner F, Malagó M, et al. Clinical trial: switch to combined mycophenolate mofetil and minimal dose calcineurin inhibitor in stable liver transplant patients-assessment of renal and allograft function, cardiovascular risk factors and immune monitoring. Aliment Pharmacol Ther 2007;26:1195-1208. doi: 10.1111/j.1365-2036.2007.03466.x.

[63] Poonja Z, Brisebois A, van Zanten SV, Tandon P, Meeberg G, Karvellas C]. Patients with cirrhosis and denied liver transplants rarely receive adequate palliative care or appropriate management. Clin Gastroenterol Hepatol 2014;12:692-698. doi: 10.1016/j.cgh.2013.08.027. 